\title{
Optimization of an Input Filter for a Three- Phase Matrix Converter
}

\author{
G.BOZTAS
}

\begin{abstract}
This study includes an optimization of the input filter for three-phase matrix converters. An input filter effects on the power factor while improving the Total Harmonic Distortion (THD) of the input current. Unity power factor being one of the most important advantages of matrix converters will be eliminated if this is not taken into consideration. For this reason, an optimization was used by taking both parameters into consideration in this study. A Particle Swarm Optimization (PSO) algorithm was used in order to reduce the THD of the input current about $3 \%$ with nearly unit power factor as 0.985 . The first of the optimization objective functions is to decrease the THD of the input current, and the second is to increase the power factor. The matrix converter was used for a constant frequency and modulation by using the switching strategy of Venturini Method and feeds an RL load. The optimized input filter was analyzed in detail in MATLAB/SimPowerSystems environment and examined in the results. Additionally, FFT spectra of the input and output waveforms are given in the results. Thus, the most suitable input filter was obtained for this system.
\end{abstract}

Index Terms-Matrix converter, Venturini Method, Power Factor, Input Filter, Harmonic Distortion.

\section{INTRODUCTION}

$\mathrm{M}$ ATRIX CONVERTER obtained with the development of the forced commutated cycloconverter based on bidirectional fully controlled switches consists of semiconductor elements and converts three-phase AC line voltages to three-phase variable voltage and frequency outputs [1], [2]. This converter consisting of 9 bidirectional switches is arranged in order to connect any of the output lines of the converter to any of the input lines. The topology of the matrix converter was first proposed by Gyugi in 1976 [3]. The matrix converter was not very popular in the industry in the past due to current commutation problems between switches, using much number of component and difficulties in the control algorithm. Many researchers developed matrix converter control algorithms based on mathematical principles after Venturini's first matrix converter study in 1980. PWM modulation strategies of the matrix converter are based on the studies of Alesina and Venturini.

GULLU BOZTAS, is with Department of Electrical \& Electronics Engineering, Faculty of Technology, Firat University, Elazig, Turkey, (e-mail: gulluboztas@gmail.com).

iD https://orcid.org/0000-0002-1720-1285

Manuscript received July 03, 2020; accepted July 30, 2020.

DOI: $\underline{10.17694 / \text { bajece. } 763403}$
The matrix converters have a more advanced potential compared to conventional voltage source inverters [4], [5]. The output waveform of the matrix converter is obtained by using a suitable PWM signal, similar to a standard inverter. However, in matrix converters, the input of the converter is fed from a three-phase constant frequency and voltage $\mathrm{AC}$ source instead of a fixed DC voltage source. These converters have no DC connection. The output voltages of the matrix converter are generated directly from the input voltages due to the lack of energy storage elements between input and output of the converter [6]. These converters have higher reliability, longer life and smaller design than inverters due to the lack of large reactive energy storage components such as bulky and limited-life electrolytic capacitors.[1], [7], [8]. These converters are able to naturally transfer regenerative energy back to the source without the need for any additional components or algorithms because matrix converters have bidirectional switches [9]-[11]. These converters can operate at all four quadrants of the torque-speed region due to their regeneration features [4], [12]. The matrix converter has a sinusoidal input current and this converter can operate at the unit displacement factor by depending on the modulation technique regardless of the power factor of the load. These converters can be used in large energy conversion systems such as motor drives, variable frequency wind generators and aircraft applications.

Output waveforms of the converter are affected from high frequency distortion in the input current of the converter. Input filters are often used to improve input current quality and reduce input voltage distortion in power converters. The effect of the filters between the input side of a power supply and input side of a matrix converter has become a major issue of matrix converter researches [13]. Input current filters are placed in the input of the matrix converter in order to prevent unwanted high frequency current components [7], [8], [12], [14], [15]. Passive LC filter is used as matrix converter input filter. Input filter designs for the matrix converter provide unity power factor on the power supply side by improving the quality of the main currents having sinusoidal waveforms containing low harmonic components and reducing the distortion of the input voltages provided to the Matrix converter module [5], [16]-[19]. Additionally, the input filter significantly reduces electromagnetic interference in the matrix converter [7], [12], [20].

Optimization techniques are widely in order obtain optimum parameters for the systems used in many engineering applications. Optimization is basically a mathematical technique for finding the maximum or minimum points of the 
functions in some feasible regions. Today, many different optimization techniques are used in many areas [21]-[26]. Particle Swarm Optimization (PSO) is a powerful optimization method shown experimentally. This method provides good results for most optimization problems. PSO has obtained increasing popularity in the last two decades [27]. PSO is a valuable meta-heuristic approach used in scientific fields with complex optimization problems. Thanks to its simplicity, PSO has an algorithm network that can be used easily even by nonexpert researchers. This situation led to increased popularity of PSO. It also allows for easy parallelization using modern highperformance computer systems. It was first proposed by Eberhart and Kennedy in 1995 [28]-[30]. PSO algorithm is very popular due to simple calculation and sharing of information. Using an optimization method such as PSO, the solution can be produced without using the gradient of the function to be optimized. It is a great advantage to use such a method if the gradient is troublesome to derived in the algorithm [31]. The PSO algorithm has two different stages. The other is called as the update phase while the first is called as the start phase. Particles called as individuals spread into a multi-dimensional search space in the algorithm. Each individual shows a suitable solution for the problem which can be optimized. The performance function of the problem represents the fitness function of the PSO algorithm [32].

In this study, the PSO algorithm is used to optimize the power factor together with the input current harmonics of a matrix converter. The difficulty of this optimization problem; it negatively effects the power factor while increasing the component values of the input filter to improve the input current harmonic of the matrix converter. The matrix converter can operate on a unit power factor due to its nature. However, the filter used at the input makes it impossible to operate on the unit power factor. In this paper, a matrix converter input filter was optimized for the input current Total Harmonic Distortion (THD) value below 5\%, which can operate close to the unit power factor. The input filter optimized for the matrix converter was tested for different output frequencies and 0.98 power factor value with $3 \%$ current THD value was obtained in this study. It is shown that the THD value remains constant in all cases when the output voltage and current of the converter is analyzed. Additionally, all swarm formation during optimization were examined graphically and they were shown to reach the optimum point. This study provides a suitable solution for one of the engineering problems. In the design of such nonlinear systems, quite demanding mathematical analysis is required. However, this study has shown that optimization methods are very useful solutions for such applications.

\section{MATRIX CONVERTER}

The structure of the matrix converter consisting of 9 bidirectional common collector switches that allow any output phase to be connected to any input phase is given in Fig.1.

The output voltages of the matrix converter are generated directly from the input voltages due to the lack of energy storage elements between inputs and outputs of the converter. The absence of a DC-link capacitor is one of the main advantages of the matrix converter because DC-link capacitor increases cost and volume of the system. This converter can transfer regenerative energy back to the source without the need for any additional elements or algorithms because the converter has bidirectional switches. The amplitude of the matrix converter output voltage limits to $86.6 \%$ amplitude of input voltage. However, higher output voltages can be obtained with overmodulation causing input current distortion.

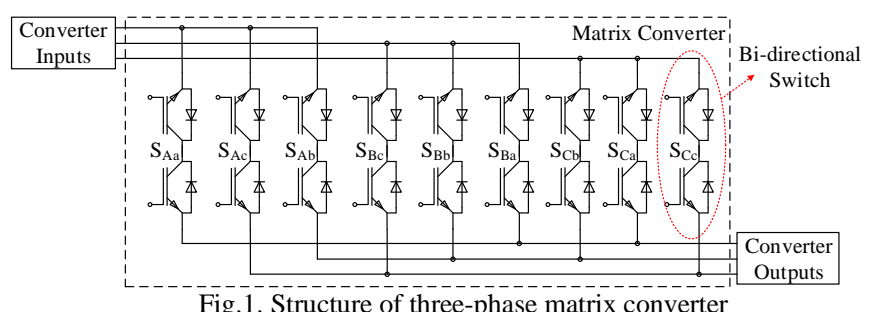

It is necessary to determine turn on/off times with sequences of the switches in order to obtain from a constant amplitude and frequency source to an adjustable amplitude and frequency output. Additionally, it is desirable to be able to operate with maximum amplitude and low total harmonic distortion. Therefore, some modulation algorithms were developed for matrix converter. Modulation algorithms used in matrix converter can be listed as Venturini, Scalar and Space Vector. In this paper, it is used switching strategy of Venturini algorithm [33].

Venturini method provides full control of output voltages and input power factor. Maximum voltage transfer ratio of the Venturini algorithm is 0.866 and this algorithm needs to output power factor information in order to control input power factor [34]. The output voltage and the duty cycle for the switch connected between the input phase $\beta$ and the output phase $\gamma$ in the unit input displacement factor are given in Eq. (1)-(3).

$$
\begin{gathered}
T_{\beta \gamma}=T_{s}\left[\frac{1}{3}+\frac{2 V_{o \gamma} V_{i \beta}}{3 V_{i m}^{2}}+\frac{2 q}{9 q_{m}} \sin \left(\omega_{i} t+\psi_{\beta}\right) \sin \left(3 \omega_{i} t\right)\right] \\
V_{o \gamma}=q V_{i m} \cos \left(\omega_{o} t+\psi_{\gamma}\right)-\frac{q}{6} V_{i m} \cos \left(\omega_{o} t\right) \\
+\frac{q}{4 q_{m}} V_{i m} \cos \left(\omega_{i} t\right) \\
V_{i m}=\sqrt{\frac{V_{A}^{2}+V_{B}^{2}+V_{C}^{2}}{1.5}}
\end{gathered}
$$

where maximum voltage ratio and desired voltage ratio are $q_{m}$ and $q . \psi_{\beta}$ and $\psi_{\gamma}$ are $0,2 \pi / 3,4 \pi / 3$ input phase difference and output phase difference, respectively. $\omega_{o}$ is angular velocity of the output frequency while $\omega_{i}$ is angular velocity of the input frequency. $V_{A}, V_{B}$, and $V_{c}$ are instantaneous input voltage and $V_{i m}$ is maximum input voltage.

Matrix converters generate current harmonics injected back into the $\mathrm{AC}$ system. The current harmonics can cause voltage distortion of the AC system. Input filter obtained with reactive energy storage component is used in order to reduce harmonics generated by matrix converters [35]. 


\section{PSO ALGORITHM FOR FILTER OPTIMIZATION}

A standard PSO algorithm performs searching using particle swarm during the iteration. In order to find the optimum solution, each particle is moved to its best position in the previous step [36]. The previous best position and the best global position are determined in Eq. (4).

$$
\begin{gathered}
\operatorname{pbest}(i, t)=\underset{k=1, \ldots, t}{\arg } \min \left[f\left(P_{i}(k)\right)\right] i \in\left\{1,2, \ldots, N_{p}\right\} \\
\operatorname{gbest}(i, t)=\underset{\substack{i=1, \ldots, N_{p} \\
k=1, \ldots, t}}{\arg \min }\left[f\left(P_{i}(k)\right)\right]
\end{gathered}
$$

where $i$ is the particle index, $N_{p}$ is the total number of particles, $t$ is the present iteration number, $f$ is the fitness function, and $P$ is the position of the particle. The velocity and position of particles are calculated using Eq. (6) and Eq. (7).

$$
\begin{gathered}
V_{i}(t+1)=\omega V_{i}(t)+c_{1} r_{1}\left(\operatorname{pbest}(i, t)-V_{i}(t)\right) \\
+c_{2} r_{2}\left(\operatorname{pbest}(t)-P_{i}(t)\right) \\
P_{i}(t+1)=P_{i}(t)+V_{i}(t+1)
\end{gathered}
$$

The velocity denotes as $V$ and the inertia weight used to balance the global exploration and local exploitation denotes with $\omega$. Uniformly distributed random variables denote $r_{1}$ and $\mathrm{r}_{2}$. Positive constant parameters called "acceleration coefficients" which are denoted as $c_{1}$ and $c_{2}$.

PSO algorithm can be examined in 8 steps as given below;

Step 1. Each particle is started randomly $P_{i}(0) \sim U($ Lower Bounds, Upper Bounds).

Step 2. Fitness function is evaluated.

Step 3. The fitness function is calculated.

Step 4. Particles are sorted and the best position of each particle is determined at each iteration.

Step 5. The position and velocity of each particle are modified.

Step 6. New positions of the particles are evaluated.

Step 7. If (the number of iterations < maximum) go to Step 1.

Step 8. Choose the particle that gets the best performance $\left(\operatorname{gbest}(t)=P_{i}(t)\right)$.

A simulation environment was created using MATLAB for a three-phase matrix converter for optimization process. This simulation system consists of a three-phase fixed voltage source, network filter (input filter), matrix converter, and RL load as shown in Fig.2. The matrix converter was operated for a constant 0.8 modulation index by using the modified Venturini algorithm during optimization process. $380 \mathrm{Vrms}$ (phase-phase), $50 \mathrm{~Hz}$ voltage source was used as input voltage. The input filter has a widely preferred LC filter connection structure as shown in the figure. The $L$ inductance and $C$ capacitor values were optimized by using two objective function. One of them is determined by approximating THD value to zero and the other is determined by approximating power factor value to 1 . The objective (fitness) function is given in Eq. (8).

$$
\mathrm{f}(t)=0.5(1-P F)+0.5 I_{T H D} / 100
$$

The structure of the optimization loop is given in Fig.3. First, the PSO operates the system with a random initial LC value. Then, based on the PSO progression, an online structure is obtained by sending the analysis results to the PSO algorithm for each new LC value. The results of the progress obtained with optimization are presented in the Fig.4. As seen in the optimization results, the THD value of the input current is decreased while the power factor value is increased to 1. As a result of optimization, inductance and capacitor values of the input filter were obtained as $9.99 \mathrm{mH}$ and $12.8055 \mu \mathrm{F}$, respectively.

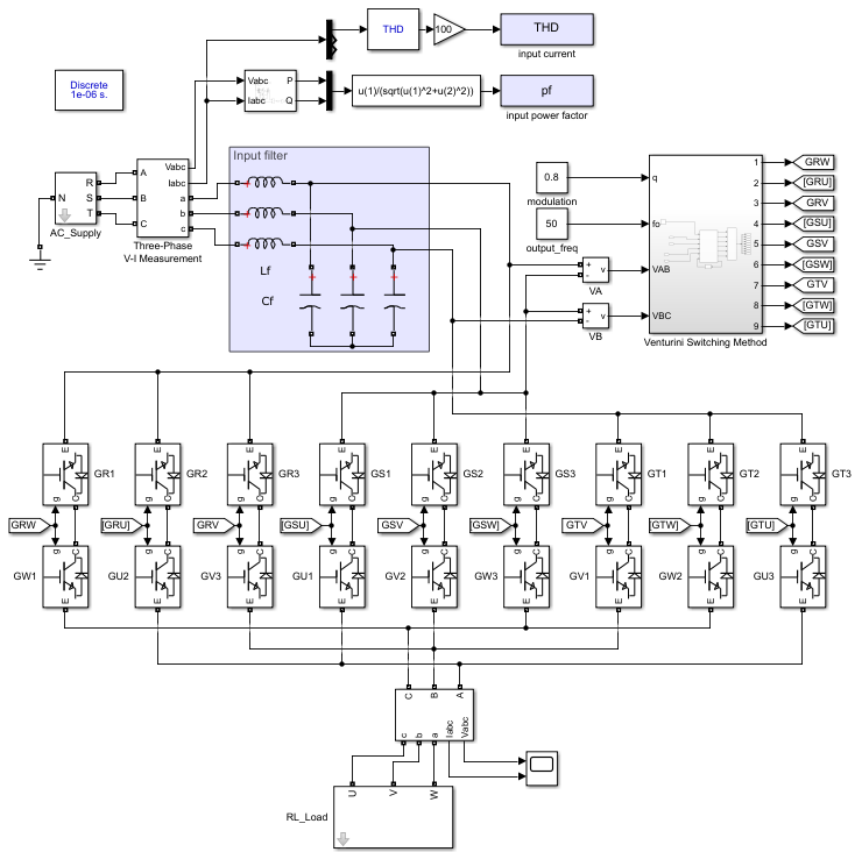

Fig.2. Structure of three-phase matrix converter

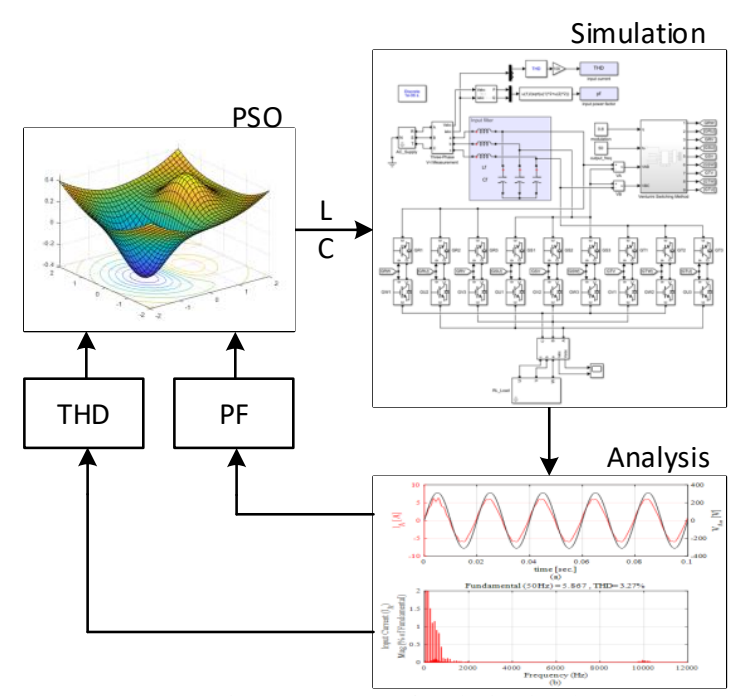

Fig.3. Structure of optimization loop 


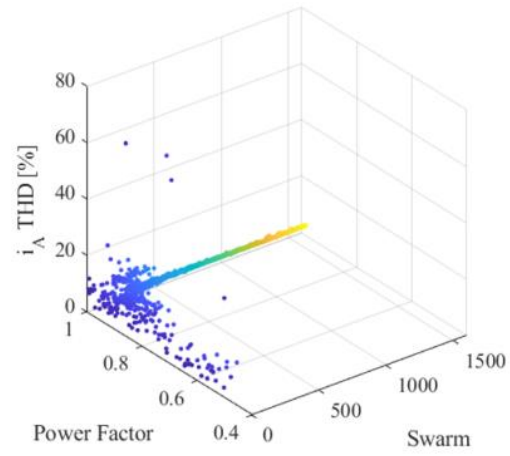

a)

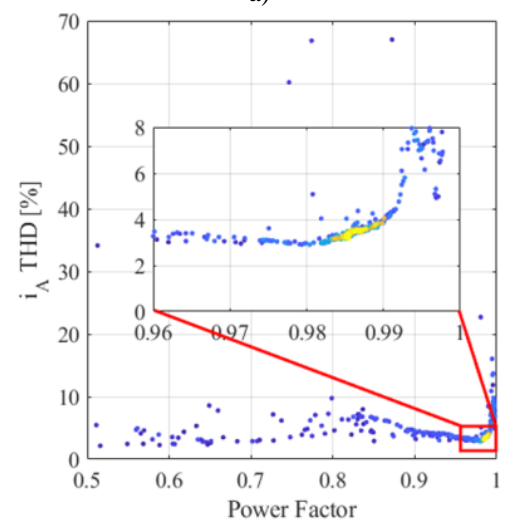

b)

Fig.4. a) Progression of power factor and $I_{A}$ THD according to $\mathrm{PSO}, \mathrm{b})$ Progression of fitness functions

\section{ANALYSIS OF OPTIMIZED SYSTEM}

The waveforms of the input current and input voltage of the system operated without input filter are given in Fig.5. The input current signal has a very high harmonic content. The distortion of the input current mostly occurs around the switching frequency of $10 \mathrm{kHz}$ when the harmonic spectrum is analyzed as seen in Fig.5a. The THD value of the input current is calculated around $67 \%$. The input current THD value is generally around $90 \%$, because of the uncontrolled rectifier structure on the input side of the inverters. Therefore, this value can be said to be quite low compared to input current THD of a standard inverter.

IEEE Std 519-1992 report provides harmonic content limits in power systems. Additionally, detailed information about harmonics can be accessed using IEEE Recommended Practice and Requirements for Harmonic Control in Electric Power Systems report [37], [38]. The current harmonic limits are determined according to the short circuit current strength of the system. Additionally, Total Demand Distortion (TDD) value is analyzed instead of THD value while determining these values. TDD can be defined as harmonic current distortion in \% of maximum demand load current about 30minute demand. It can be seen that the acceptable value for this system is $5 \%$. when the report is analyzed.

The inductance and capacitor values can be used as about $10 \mathrm{mH}$ and $12 \mu \mathrm{F}$ when the optimized values of the filter are organized as engineering notation. The system is operated with the filter values obtained as a result of optimization. The input waveforms of the matrix converter are analyzed in Fig.6. As seen in Figure 6a, current and voltage revisions oscillate
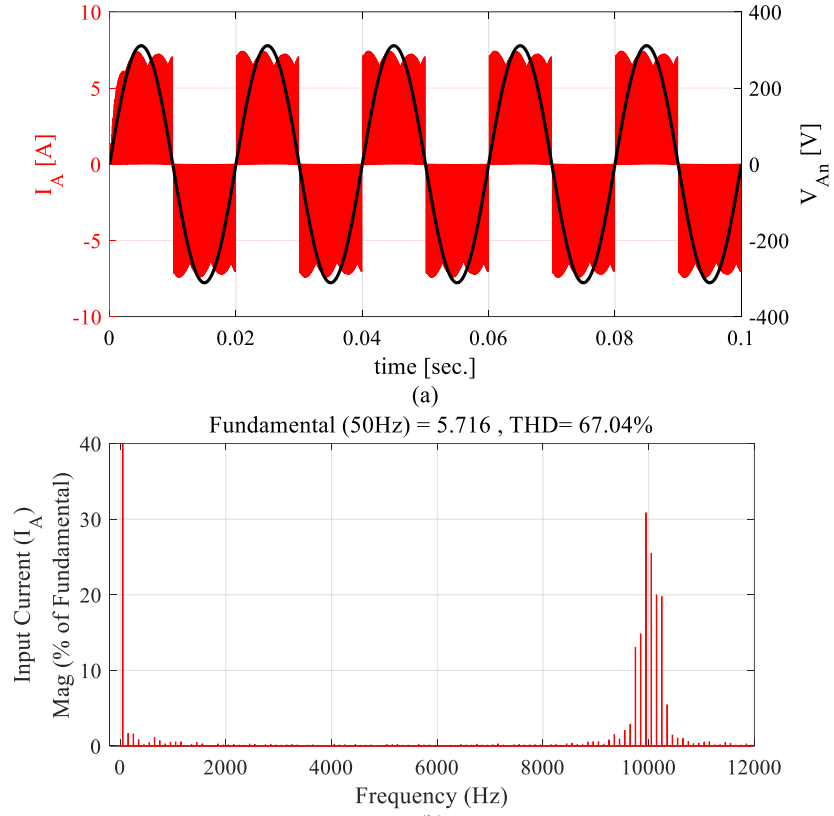

(b)

Fig.5. Without input filter; a) Waveform of input current with grid voltage, b) Harmonic spectrum of input current

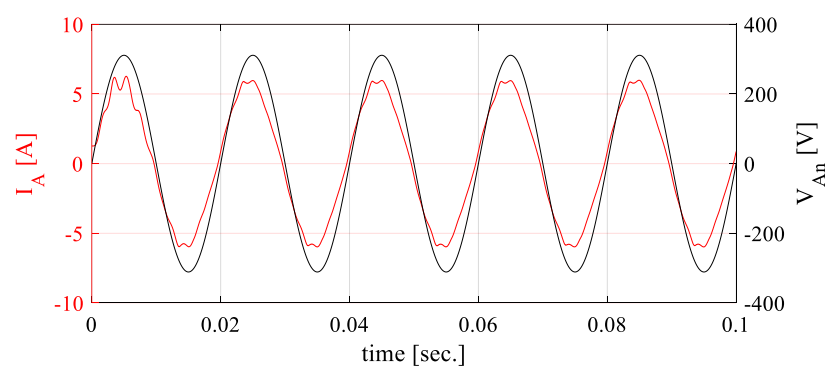

(a)

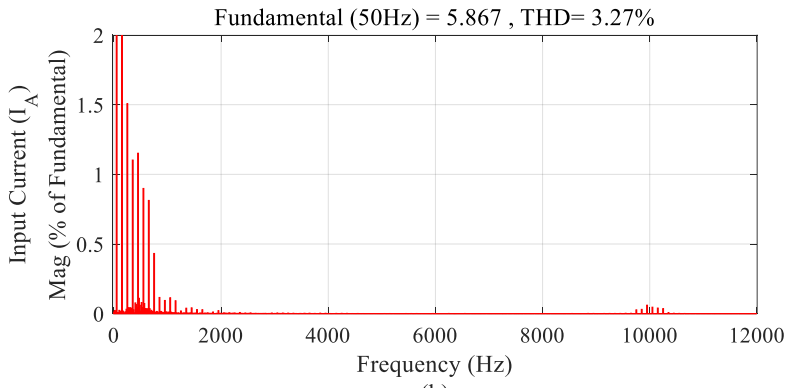

(b)

Fig.6. With optimized input filter; a) Waveform of input current with grid voltage, b) Harmonic spectrum of input current

nearly overlap. The power factor of the system was calculated as 0.985 . The reason for a small notch at the top of the current signal in the first period is the nonlinear structure in the system in the transient state. It can be seen that symmetrical oscillation is obtained in later periods. It is seen that a very low THD value can be obtained around $3 \%$ when the harmonic of the current signal is analyzed as shown in Fig.6b. The harmonic magnitude being closest to the fundamental harmonic is approximately $2 \%$ of the fundamental harmonic value. The most dominant harmonic magnitude value is nearly $30 \%$ of the fundamental harmonic value when the input filter was not used as shown in Fig.5b. Therefore, it is necessary to 
say that the switching frequency is dominant in the non-filter condition. Additionally, the system is analyzed for different output frequency from $10 \mathrm{~Hz}$ to $70 \mathrm{~Hz}$ as shown in Table 1 . As expected, the THD values of both input and output signals are similar. The input current THD value is remained below 3 $\%$ for different output frequencies. The power factor values are obtained close to the unit power factor value. Thus, in this study, the aimed low input current harmonic content and unit power factor value were successfully obtained by using an appropriate optimization. As the modulation index increases, THD values of the output voltage and output current decrease while the power factor the input current THD increase. As the modulation index decrease, THD values of the output voltage, output current and input current increase while the power factor decreases.

TABLE I

ANALYSIS OF INPUT FILTER FOR DIFFERENT OUTPUT

\begin{tabular}{|c|c|c|c|c|}
\hline \multirow{2}{*}{$\begin{array}{c}\text { Output } \\
\text { Frequency }\end{array}$} & \multicolumn{2}{|c|}{$\begin{array}{c}\text { Converter } \\
\text { Input }\end{array}$} & \multicolumn{2}{c|}{$\begin{array}{c}\text { Converter } \\
\text { Output }\end{array}$} \\
\cline { 2 - 5 } & $\begin{array}{c}\mathbf{I}_{\mathbf{A}} \\
\text { THD }\end{array}$ & $\begin{array}{c}\text { Power } \\
\text { Factor }\end{array}$ & $\begin{array}{c}\mathbf{V}_{\mathbf{a b}} \\
\text { THD }\end{array}$ & $\begin{array}{c}\mathbf{I}_{\mathbf{a}} \\
\text { THD }\end{array}$ \\
\hline Hz & $\mathbf{\%}$ & - & $\boldsymbol{\%}$ & $\mathbf{\%}$ \\
\hline 10 & 4.09 & 0.989 & 64.04 & 2.72 \\
\hline 20 & 4.16 & 0.993 & 64.03 & 2.24 \\
\hline 30 & 4.75 & 0.988 & 63.42 & 1.96 \\
\hline 40 & 3.95 & 0.988 & 63.30 & 1.94 \\
\hline 50 & 3.27 & 0.985 & 64.81 & 1.90 \\
\hline 60 & 4.63 & 0.984 & 64.69 & 2.16 \\
\hline 70 & 4.30 & 0.9834 & 62.31 & 2.22 \\
\hline
\end{tabular}

\section{CONCLUSION}

A study was carried out to improve the power factor and current harmonic content values, which are important parameters for power electronics systems. These parameters can be improved in order to obtain desired values using a passive input filter with inductance and capacitor. This conversion cannot be performed in one step by using an inverter if AC-AC conversion is to be obtained using a voltage-source inverter. Therefore, the input filter used in this conversion must be quite large. In this study, a matrix converter structure with many advantages was preferred. This system can provide a converter structure with very low input harmonic content and unit power factor, especially by using very small input filter.

It is generally preferred in order to calculate the natural frequency value in order to determine the inductance and capacitor values in the input filter. However, this approach improves the harmonic content in the input current while significantly reducing the power factor. This eliminates the ability to operate on the unit power factor being one of the most important features of the matrix converter. Therefore, filter values were optimized by using the PSO algorithm in this study. The optimization goal is to reduce the THD value of the input current and keep the power factor close to the unit power factor value. An optimization algorithm was performed in order to obtain a realistic value by operating with a simulation environment created online. The system was analyzed for optimized $\mathrm{L}$ and $\mathrm{C}$ values and different output frequencies. As a result of the analysis, it was shown that the input current THD value can be kept under the $3 \%$ while the power factor value can be kept close to 1 .
Consequently, it can be said that the optimized input filter can give the desired results without disrupting the inherent properties of the matrix converter.

\section{REFERENCES}

[1] M. Hamouda, H. F. Blanchette, and K. Al-Haddad, "Unity Power Factor Operation of Indirect Matrix Converter Tied to Unbalanced Grid," IEEE Trans. Power Electron., vol. 31, 2, 2016, pp. 1095-1107,

[2] R. Kumar, A. V. Goyal, S. Srivastava, S. P. Singh, and N. Singh, "Modelling and simulation of matrix converter based DC-DC converter," in 2013 International Conference on Energy Efficient Technologies for Sustainability, ICEETS 2013, 2013, pp. 134-138.

[3] L. Gyugyi and B. R. Pelly, "Static power frequency changers: Theory, performance, and application," Computer Science, 1976.

[4] E. Watanabe, S. Ishii, E. Yamamoto, H. Hara, J. K. Kang, and A. M. Hava, "High performance motor drive using matrix converter," in IEE Colloquium (Digest), no. 72, 2000, pp. 33-38.

[5] P. Wheeler and D. Grant, "Optimised input filter design and low-loss switching techniques for a practical matrix converter," IEE Proc. Electr. Power Appl., vol. 144, 1, 1997, pp. 53-60.

[6] A. Alesina and M. G. B. Venturini, "Analysis and Design of OptimumAmplitude Nine-Switch Direct AC-AC Converters," IEEE Trans. Power Electron., vol. 4, 1, 1989, pp. 101-112.

[7] A. K. Sahoo, K. Basu, and N. Mohan, "Systematic input filter design of matrix converter by analytical estimation of RMS current ripple," IEEE Trans. Ind. Electron., vol. 62, 1, 2015, pp. 132-143.

[8] P. Wheeler, J. Clare, L. Empringham, M. Apap, and M. Bland, "Matrix converters," Power Eng. J., vol. 16, 6, 2002, pp. 273-282.

[9] K. You, D. Xiao, M. F. Rahman, and M. N. Uddin, "Applying reduced general direct space vector modulation approach of AC-AC matrix converter theory to achieve direct power factor controlled three-phase AC-DC matrix rectifier," in IEEE Transactions on Industry Applications, vol. 50, 3, 2014, pp. 2243-2257.

[10] O. Aydogmus and E. Deniz, "Design and implementation of two-phase permanent magnet synchronous motor fed by a matrix converter," IET Power Electron., vol. 10, 9, 2017, pp. 1054-1060.

[11] E. Deniz and Ö. Aydoğmuş, "Design and implementation of two-phase matrix converter," J. Fac. Eng. Archit. Gazi Univ., vol. 32, 1, 2017, pp. 9-20.

[12] H. M. Nguyen, H. H. Lee, and T. W. Chun, "Input power factor compensation algorithms using a new direct-SVM method for matrix converter," IEEE Trans. Ind. Electron., vol. 58, 1, 2011, pp. 232-243.

[13] H. H. Lee, H. M. Nguyen, and T. W. Chun, "New direct-SVM method for matrix converter with main input power factor compensation," in IECON Proceedings (Industrial Electronics Conference), 2008, pp. 1281-1286.

[14] H. Wu, H. Ge, Y. Xu, and W. Zhang, "The power factor correction of three-phase to single-phase matrix converter with an active power decoupling capacity," in IEEE Transportation Electrification Conference and Expo, ITEC Asia-Pacific 2014 - Conference Proceedings, 2014.

[15] D. Borojević, "Space Vector Modulated Three-Phase to Three-Phase Matrix Converter with Input Power Factor Correction," IEEE Trans. Ind. Appl., vol. 31, 6, 1995, pp. 1234-1246.

[16] D. Casadei, G. Serra, A. Tani, A. Trentin, and L. Zarri, "Theoretical and experimental investigation on the stability of matrix converters," IEEE Trans. Ind. Electron., vol. 52, 5, 2005, pp. 1409-1419.

[17] D. Casadei, G. Serra, A. Tani, and L. Zarri, "Effects of input voltage measurement on stability of matrix converter drive system," IEE Proc. Electr. Power Appl., vol. 151, 4, 2004, pp. 487-497.

[18] D. Casadei et al., "Large-signal model for the stability analysis of matrix converters," IEEE Trans. Ind. Electron., vol. 54, 2, 2007, pp. 939-950.

[19] J. W. Kolar, F. Schafmeister, S. D. Round, and H. Ertl, "Novel threePhase AC-AC sparse matrix converters," IEEE Trans. Power Electron., vol. 22, 5, 2007, pp. 1649-1661.

[20] K. Yamada et al., "Integrated filters and their combined effects in matrix converter," in Conference Record - IAS Annual Meeting (IEEE Industry Applications Society), 2005, vol. 2, pp. 1406-1413.

[21] F. B. Demir, T. Tuncer, and A. F. Kocamaz, "Lojistik-Gauss Harita Tabanlı Yeni Bir Kaotik Sürü Optimizasyon Yöntemi," Anatol. J. Comput. Sci., vol. 4, 1, 2019, pp. 47-53. 
[22] F. B. Demir, T. Tuncer, A. F. Kocamaz, and F. Ertam, "A survival classification method for hepatocellular carcinoma patients with chaotic Darcy optimization method based feature selection," Med. Hypotheses, vol. 139, 2020.

[23] F. B. Demir, T. Tuncer, and A. F. Kocamaz, "A chaotic optimization method based on logistic-sine map for numerical function optimization," Neural Comput. Appl., 2020, pp. 1-13.

[24] F. B. Demir, T. Tuncer, and A. F. Kocamaz, "Lojistik-singer harita tabanli yeni bir kaotik sürü optimizasyon yöntemi," in 2019 International Conference on Artificial Intelligence and Data Processing Symposium, IDAP 2019, 2019.

[25] R. Çelikel and M. Özdemir, "A method for current control of the flywheel energy storage system used in satellites," Teh. Vjesn., vol. 26, 3, 2019, pp. 631-638.

[26] M. GEDIKPINAR and Ö. ATDOĞMUŞ, "Design of a self-starting hybrid permanent magnet hysteresis synchronous motor connected directly to the grid," TURKISH J. Electr. Eng. Comput. Sci., vol. 25, 2017, pp. 1657-1668.

[27] K. E. Parsopoulos, "Particle Swarm Methods," in Handbook of Heuristics, Springer International Publishing, 2015, pp. 1-47.

[28] J. Kennedy; R. Eberhart, "Particle swarm optimization," in In: Proceedings of the IEEE international joint conference on neural networks, 1995, vol. 4, no. 6, pp. 1942-1948.

[29] Y. Shi and R. Eberhart, "Modified particle swarm optimizer," in Proceedings of the IEEE Conference on Evolutionary Computation, ICEC, 1998, pp. 69-73.

[30] R. Eberhart and J. Kennedy, "New optimizer using particle swarm theory," in Proceedings of the International Symposium on Micro Machine and Human Science, 1995, pp. 39-43.

[31] M. Erik and H. Pedersen, "Good Parameters for Particle Swarm Optimization,” Technical Report no. HL1001, 2010.

[32] M. Agrawal, M. Mishra, and S. P. S. Kushwah, "Association rules optimization using improved PSO algorithm," 2015 International Conference on Communication Networks (ICCN), 2015, pp. 395-398.

[33] M. G. B. Venturini, "Solid-State Power Conversion: A Fourier Analysis Approach to Generalized Transformer Synthesis," IEEE Trans. Circuits Syst., vol. 28, 4, 1981, pp. 319-330.

[34] O. Aydogmus and S. Sünter, "Implementation of EKF based sensorless drive system using vector controlled PMSM fed by a matrix converter," Int. J. Electr. Power Energy Syst., vol. 43, 1, 2012, pp. 736-743.

[35] A. Popovici, V. Popescu, M. I. Băbăiţă, D. Lascu, and D. Negoitescu, "Modeling, Simulation and Design of Input Filter for Matrix Converters," in 2005 WSEAS Int. Conf. on on Dynamical Systems and Control, 2005, pp. 439-444.

[36] Y. Zhang, S. Balochian, P. Agarwal, V. Bhatnaga, and O. J. Housheya, "Artificial Intelligence and Its Applications," Math. Probl. Eng., vol. 2014, 2014, pp. 1-10.

[37] T. M. Blooming and D. J. Carnovale, "Application of IEEE STD 5191992 harmonic limits," in IEEE Conference Record of Annual Pulp and Paper Industry Technical Conference, 2006.

[38] D. Committee, I. Power, and E. Society, "IEEE Std 519-2014 (Revision of IEEE Std 519-1992)," IEEE Std 519-2014 (Revision IEEE Std 5191992), vol. 2014, 2014, pp. 1-29.

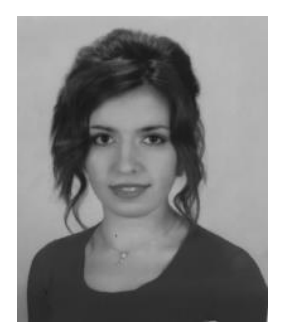

BIOGRAPHIES

GULLU BOZTAS received the B.S. (2011), M.S. (2015), and Ph.D. (2019) degree in electric-electronics engineering from the University of Firat. Since 2013, she has been a Research Assistant in Department of Electrical \& Electronics Engineering, Faculty of Technology, Firat University, Elazig, Turkey. Her research interests include power electronics and electric machines. 